\title{
A Chlorophyll Fluorescence Screening Test to Evaluate Chilling Tolerance in Tomato
}

\author{
Mark A. Walker \\ Department of Crop Science, University of Guelph, Guelph, Ont. N1G \\ 2W1, Canada
}

Dale M. Smith

H.J. Heinz Company of Canada, Ltd., Erie Street South, Leamington, Ont. N8H 3W8, Canada

\author{
K. Peter Pauls and Bryan D. McKersie \\ Department of Crop Science, University of Guelph, Guelph, Ont. N1G \\ 2W1, Canada \\ Additional index words. Lycopersicon esculentum, Lycopersicon hirsutum, Solanum \\ lycopersicoides, temperature stress
}

\begin{abstract}
The chilling tolerance of commercial Lycopersicon esculentum cultivars (H2653, H722), Solanum lycopersicoides, an $F_{1}$ hybrid of S. lycopersicoides $\times$ Sub-Arctic Maxi, and $25 \mathrm{BC}_{2} \mathrm{~F}_{2}$ lines of $L$. hirsutum $\times \mathrm{H722}$ (backcrossed twice to $\mathrm{H722}$ ) was evaluated using a chlorophyll fluorescence assay. The ratio of the initial to the peak fluorescence (Fo : Fp) measured from fully expanded leaves was chosen as an indicator of plant health. Chilling induced an increase in Fo : Fp that was correlated with the sensitivity of the plant to low-temperature stress. Values of Fo : Fp remained low for cold-treated $S$. lycopersicoides and the $F_{1}$ hybrid, which showed few symptoms of chilling-related damage, whereas the commercial cultivars, which were essentially intolerant to low temperatures, had large increases in Fo : Fp. A full range of Fo : Fp values was measured in the $25 \mathrm{BC}_{2} \mathrm{~F}_{2}$ lines, indicating that some chilling tolerance from the $L$. hirsutum parent was expressed by plants in these populations.
\end{abstract}

Chilling injury is a physiological disorder that occurs in plant species of tropical or subtropical origin when exposed to temperatures between 0 and $12 \mathrm{C}$. The severity and length of time required to cause an irreversible dysfunction are generally reduced as the temperature is lowered (13). Chilling resistance or tolerance can be defined as the ability of a chilling-sensitive species to counteract

Received for publication 15 Aug. 1988. Supported by a grant from Natural Sciences and Engineering Research Council of Canada, H.J. Heinz Co., and the Ontario Vegetable Growers' Marketing Board. The cost of publishing this paper was defrayed in part by the payment of page charges. Under postal regulations, this paper therefore must be hereby marked advertisement solely to indicate this fact. or withstand exposure to chilling stress (19).

Considerable interest has been shown in the use of room-temperature chlorophyll fluorescence measurements to evaluate photosystem integrity following environmental stresses $(6,20,21)$. This chlorophyll fluorescence test, which uses the chlorophyll molecule as an endogenous probe of chloroplast functionality, has been used to select chilling-resistant maize cultivars (7).

Chilling tolerance has been found in wild relatives of Lycopersicon and Solanum spp. that grow at high elevations $(8,20,23)$. The introgression of this trait into the cultivated tomato might be achieved by making interspecific crosses and selecting for agronomic types that exhibit chilling tolerance in advanced generations. The primary difficulty 


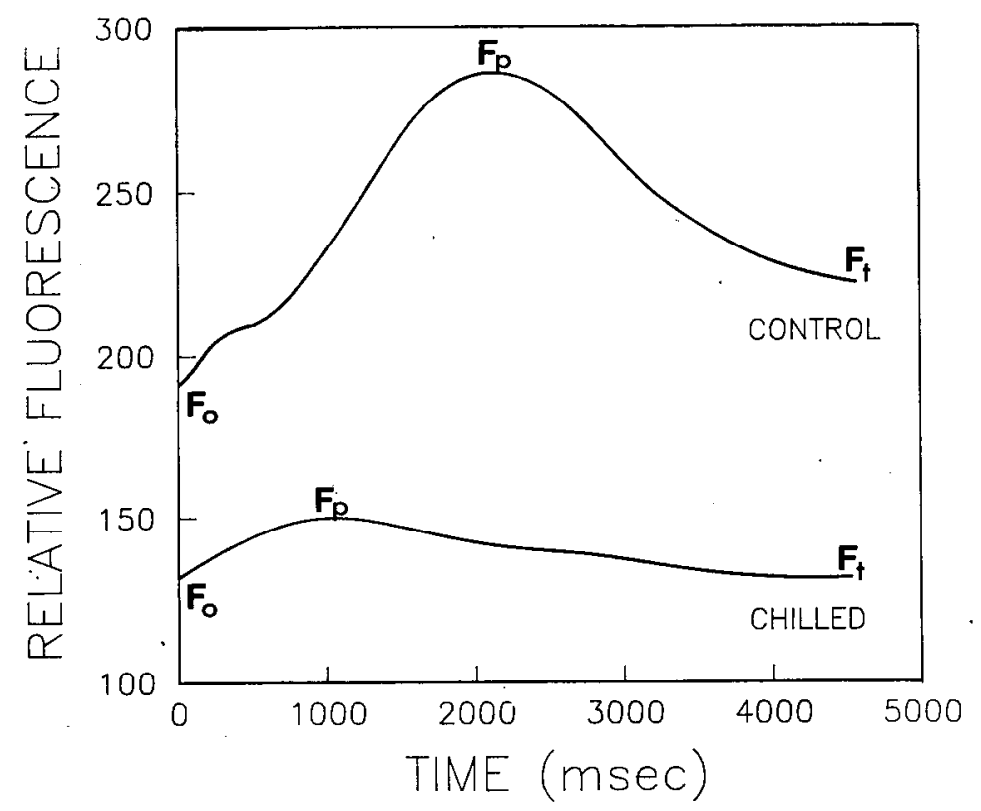

Fig. 1. An example of a chlorophyll fluorescence induction curve obtained from the adaxial leaf surface of L. esculentum cv. H722. Fo: initial fluorescence, Fp: peak fluorescence, Ft: terminal fluorescence. Control plant was maintained at $25 \mathrm{C}$. Chilled plant was maintained at $2 \mathrm{C}$.

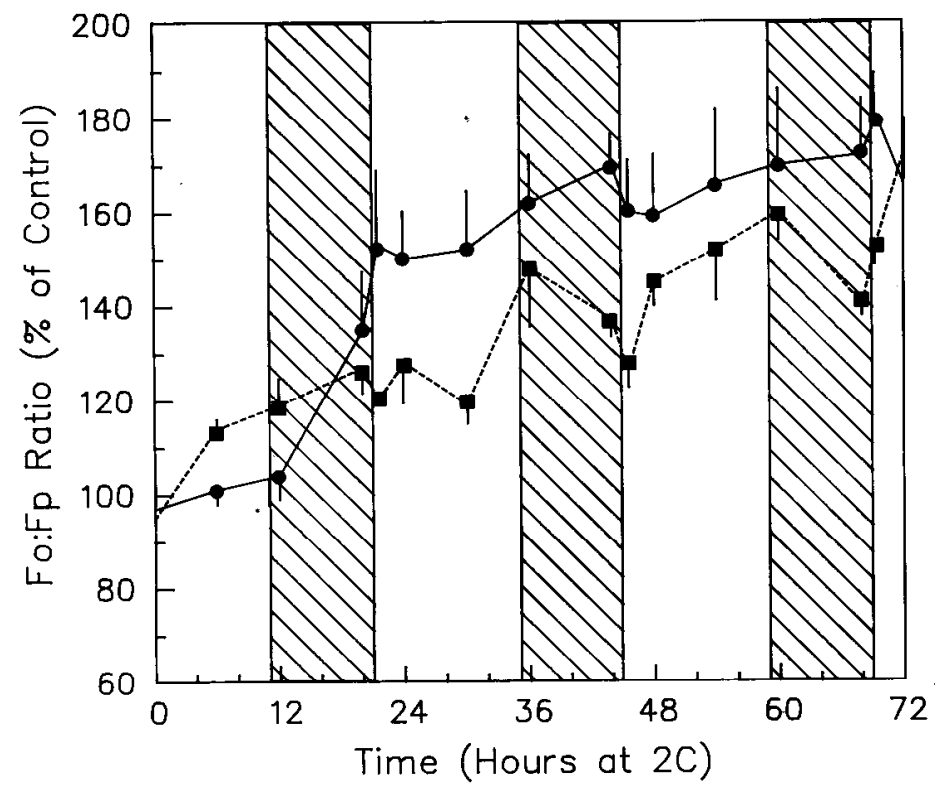

Fig. 2. Changes in the Fo : Fp ratio of $L$. esculentum $\mathrm{cv}$. H722 and $L$. hirsutum expressed as a percent of control during a low-temperature treatment of $2 \mathrm{C}$ for $72 \mathrm{hr}$. $\mathrm{H} 722$

Shaded area represents the dark period. Values represent the mean of three replications \pm SE.

in such a program is the development of a simple screening procedure to identify plants with enhanced chilling tolerance in large segregating populations encountered in plant breeding;

Kamps et al. (8) have evaluated the correlation among several screening procedures for chilling sensitivity in nine genotypes of tomato, including: a) chlorophyll fluorescence, b) a visual rating of leaflet samples, c) electrolyte leakage, and d) a visual rating of intact plants. They concluded that subjective assays were less precise than quantitative assays and that the chlorophyll fluorescence assay was the most precise test used in their study.

The purpose of this study was to determine if a leaf chlorophyll fluorescence-based assay could identify plants with enhanced levels of chilling tolerance in a segregating population derived from a cross between a cold-resistant $L$. hirsutum accession and a sensitive $L$. esculentum cv. H722.

Table 1 lists the material that was evaluated for chilling tolerance in the present study. Based on the report of Kamps et al. (8), cuttings of Solanum lycopersicoides, an $\mathrm{F}_{1}$ hybrid of $S$. lycopersicoides $\times$ Sub-Arctic Maxi, and $L$. hirsutum were included as representatives of chilling-resistant material.
Chilling-susceptible plants included three $L$. esculentum cultivars of Heinz commercial tomatoes, H2653, H722, and H9023 (8). This study also included $2.5 \mathrm{BC}_{2} \mathrm{~F}_{2}$ lines derived from a L. hirsutum Humb. and Bonpl. (chilling-resistant) by L. esculentum Mill. cv. H722 (chilling-sensitive) cross $\left(\mathrm{F}_{1}\right)$ made by $\mathrm{K}$. Sink, Michigan State Univ., East Lansing, that was backcrossed twice to H722. The $\mathrm{BC}_{2}$ generation was self-pollinated and seeds were harvested from plants representing a range in phenotypic expression. No evaluation of chilling tolerance was carried out before the $\mathrm{BC}_{2} \mathrm{~F}_{2}$ generation.

Four replicate experiments of 4- to 5-weekold plants were chilled in a modified freezer cabinet for $72 \mathrm{hr}$ at $2 \mathrm{C}$ with $80 \% \mathrm{RH}$ under a 14-hr photoperiod and light intensity of $300 \mu \mathrm{mol} \cdot \mathrm{s}^{-1} \cdot \mathrm{m}^{-2}$. An air exchange system was installed to provide constant $\mathrm{CO}^{2}$ levels. Control plants were maintained under identical conditions except for temperature, which was held at 25C. Chlorophyll fluorescence data were collected as described below. The effects of low temperature on the diurnal pattern of chlorophyll fluorescence were monitored in plants chilled at $2 \mathrm{C}$ and control plants of $\mathrm{H} 722$ and L. hirsutum held at 25C during $72 \mathrm{hr}$ under the above conditions.

To compare the response of whole plants and detached leaves to chilling temperatures, leaves of two chilling-susceptible lines ('H722', 'H9023') were excised under water and placed in flasks of distilled water. The detached leaves and whole plants were chilled as described above and chlorophyll fluorescence data were collected every $24 \mathrm{hr}$.

Chlorophyll fluorescence (CF) induction curves were measured with a plant productivity fluorometer (Model SF20, Richard Brancker Research, Ottawa, Ont.) and data were stored via an analog to digital converter (Interactive Microwave, State College, Pa.), in a personal computer. The measuring sensor, placed directly on the adaxial surface of the leaf, contained both a light-emitting diode to irradiate the leaf and a filtered photodiode to detect $\mathrm{CF}$ emissions. The irradiance output was calibrated to $20 \mu \mathrm{mol} \cdot \mathrm{s}^{-1} \cdot \mathrm{m}^{-2}$. Plants were dark-adapted for $1.5 \mathrm{~min}$ and $\mathrm{CF}$ data were collected under green light from two leaves per plant.

Figure 1 depicts typical chlorophyll fluorescence profiles of control and chilled leaves of the cold-sensitive $L$. esculentum cv. H722 after 3 days at $2 \mathrm{C}$ under a $14-\mathrm{hr}$ photoperiod. The data were collected at a rate of 1 point/ msec, with the main features of the trace being the initial fluorescence at $\mathrm{t}=1 \mathrm{msec}$ $(\mathrm{Fo})$, the peak fluorescence $(\mathrm{Fp})$, and the terminal fluorescence at $t=5 \sec \left(\mathrm{F}_{\mathrm{T}}\right)$. In the induction signal, the true Fo level is only seen when, before illumination, the first stable acceptor of PSII, $Q_{A}$, is fully oxidized. This stage can be achieved by dark adaptation for several minutes (10). These complex transients have been shown to be related to changes in photosynthetic functions (16). The rise in fluorescence to the maximum level, $F p$, reflects the reduction of $Q_{A}$ as it acts as a sink for electrons and thereby quenches fluorescence (3). Havaux and Lannoye (6) 
Table 1. Collection sites and sources for selected solanaceous species.

\begin{tabular}{|c|c|c|}
\hline Genotype & Collection site & Source \\
\hline $\begin{array}{l}\text { Solanum lycopersicoides } \\
\text { Dun. (LA 1990) }\end{array}$ & $\begin{array}{l}\text { CPI 255549, Palca, } \\
\text { Taena, Peru }\end{array}$ & $\begin{array}{l}\text { Tomato Genetics Stock } \\
\text { Center, Univ. of } \\
\text { California. Davis }\end{array}$ \\
\hline $\begin{array}{l}\text { Lycopersicon hirsutum } \\
\text { Humb. \& Bonpl. (LA 1363) }\end{array}$ & $\begin{array}{l}3200 \mathrm{~m} \text {, Alta } \\
\text { Toitaleza, Ancash, } \\
\text { Peru }\end{array}$ & $\begin{array}{l}\text { Tomato Genetics Stock } \\
\text { Center, Univ. of } \\
\text { California, Davis }\end{array}$ \\
\hline $\begin{array}{l}\text { L. esculentum Mill. cv. } \\
\text { Sub-Arctic Maxi (MSU L104) } \\
\times \text { S. lycopersicoides (LA 1990) }\end{array}$ & & $\begin{array}{l}\text { Michigan State Univ., } \\
\text { East Lansing }\end{array}$ \\
\hline $\begin{array}{l}\text { L. esculentum Mill. } \\
\text { (Heinz H722) }\end{array}$ & & H.J. Heinz Co. \\
\hline $\begin{array}{l}\text { L. esculentum Mill. } \\
\text { (Heinz H2653) }\end{array}$ & & H.J. Heinz Co. \\
\hline $\begin{array}{l}\text { L. esculentum Mill. } \\
\text { (Heinz H9023) }\end{array}$ & & H.J. Heinz Co. \\
\hline
\end{tabular}

Table 2. F values of six chlorophyll fluorescence parameters.

\begin{tabular}{lcccccc}
\hline \hline Source & Fo & Fp & $\mathrm{F}_{\mathrm{T}}$ & $\mathrm{Fp}-\mathrm{Fo}$ & $\mathrm{Fo}: \mathrm{Fp}$ & $(\mathrm{Fp}-\mathrm{Fo}) \div \mathrm{o}$ \\
\hline Genotype & $3.41^{* * *}$ & $2.17^{* *}$ & $2.77^{* *}$ & $1.59^{*}$ & $1.82^{*}$ & $1.72^{*}$ \\
\hline$* * * * * *$ Significant at $P<$ & 0.10 & 0.05 & and & 0.01 respectively & &
\end{tabular}

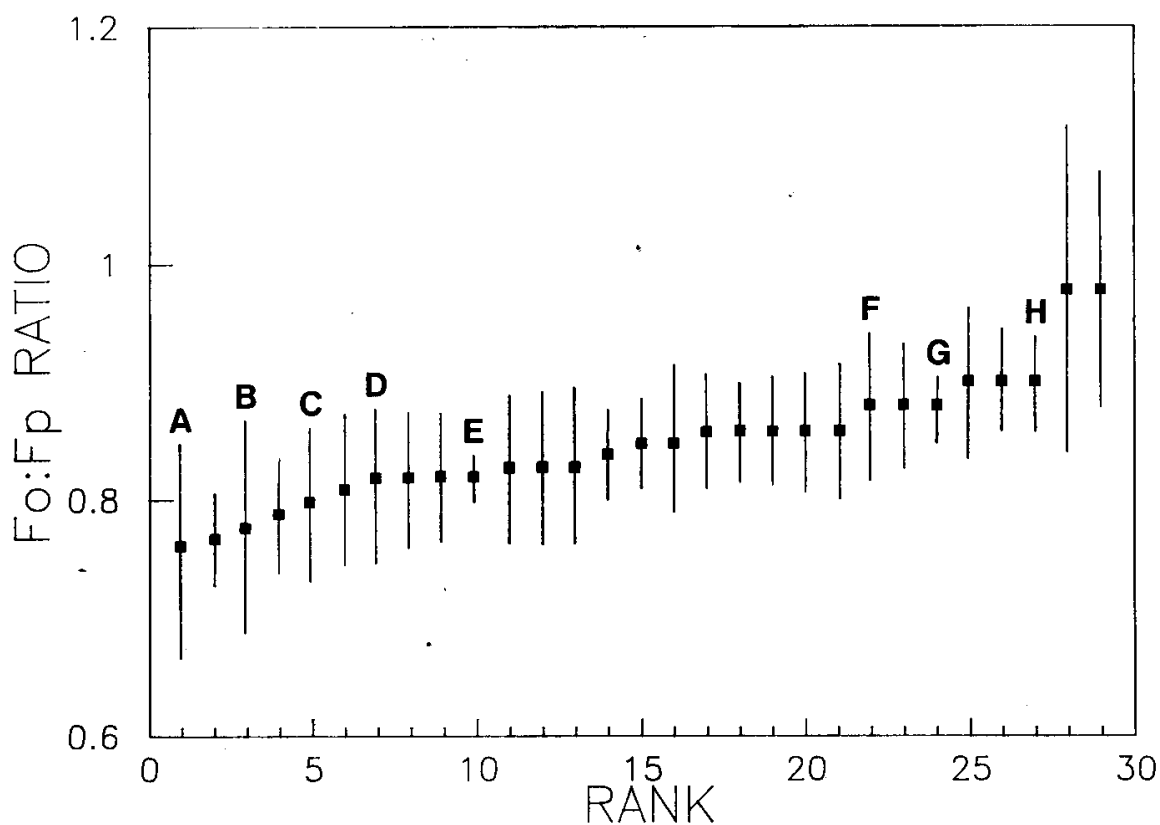

Fig. 3. The overall ranking, based on the Fo : Fp ratio, of the plant material tested following 3 days of cold treatment at $2 \mathrm{C}$. Values represent the mean \pm SE of at least four experiments. A) $S$. lycopersicoides. B) F hybrid of S. lycopersicoides $\times$ Sub-Arctic Maxi. G) L. esculentum cv. H722. $\mathrm{H})$ L esculentum cv. $\mathrm{H} 2653$. All other lines are from a $\mathrm{BC}_{2} \mathrm{~F}_{2}$ population obtained from a $L$. hirsutum $\times$ H722 cross (backcrossed twice to H722), including C) line 51558-1; D) line 51544; E) line 51553; F) line 51542.

have outlined several factors that contribute to the decline in variable fluorescence (FpFo) after Fp, including: 1) reoxidation of $Q_{A}$ generated by PSI and Calvin cycle activity $(1), 2)$ light-induced formation of a prephosphorylation high-energy state of thyalkoid membranes (9), and 3) state 1 to state 2 transition during which phosphorylation of the apoproteins of the light harvesting chlorophyll protein complexes (LHCP) of PSII modifies the interaction of the LHCP with the two photosystems (2). $\mathrm{F}_{\mathrm{T}}$ represents a steady-state level of fluorescence that is obtained after several minutes of exposure to light. In the context of this study, $\mathrm{F}_{\mathrm{T}}$ rep- resents the final fluorescence reading at 5 sec.

Table 2 shows that significant declines in Fo, Fp, and $\mathrm{F}_{\mathrm{T}}$ occur following a chilling stress of the genotypes tested. Four plants of each genotype were chilled in a completely randomized design for $72 \mathrm{hr}$ at $2 \mathrm{C}$ with $80 \%$ $\mathrm{RH}$ under a 14-hr photoperiod and light intensity of $300 \mu \mathrm{mol} \cdot \mathrm{s}^{-1} \cdot \mathrm{m}^{-2}$. The absolute values of the chlorophyll fluorescence signal were not correlated with the known tolerance levels of the resistant and susceptible materials (8), and were therefore not deemed useful as selection criteria. However, Fp - Fo, Fo : Fp, and $(\mathrm{Fp}-\mathrm{Fo}) \div \mathrm{Fo}$ were all reliable parameters that could be used to rank the tolerance level of the plant material (8). However, the Fo : Fp ratio had a higher $F$ value (Table 2) in experiments dealing with comparisons of genotypes with a wide range of chilling tolerance.

The characteristics of the chlorophyll fluorescence induction curve are modified by any factor that directly or indirectly affects photosynthetic metabolism. For example, conditions that inhibit the water-splitting side of PSII, such as chilling injury $(5,20)$, reduce the fluorescence rise above Fo in susceptible plants, such as H722. This reduction translates into an increase in the Fo : Fp ratio from $\approx 0.5$ in nonchilled leaves to values $>0.85$ after chilling. The effect on fluorescence has also been quantified as a change in the slope $(\mathrm{Fr})$ of the rising phase of the induction curve $(14,15)$. Smillie and Hetherington (21) have shown that Fr decreases or Fo : Fp increases as a result of environmental stresses and have suggested that this change represents damage occurring on the photo-oxidizing side of PSII.

The screening procedure in this study is based on the selection of plant lines that have the lowest overall Fo : Fp ratio following a treatment of $2 \mathrm{C}$ for 3 days. The assay does not provide information concerning the functionality of PSII per se, since changes in the Fo : Fp ratio are influenced by a plethora of metabolic conditions involving electrontransport capacity, ATP/NADPH pool sizes, protein phosphorylation $(4,14,15)$, as well as chilling. The Fo : Fp ratio also increases as leaves age and senesce or become chlorotic as a result of reduced nutrient supply. Therefore, to reduce the variability in the chlorophyll fluorescence profile, attention must be given to the physiological age and nutritional status of the plant material.

Figure 2 shows the effects of chilling on the diurnal changes in the Fo : Fp ratio for H722 and L. hirsutum over 3 days. During the 2nd and 3rd days of stress, the Fo : Fp ratio of the chilled susceptible $\mathrm{H} 722$ continued to increase relative to nonchilled plants. Although the Fo : Fp ratio for chilled $L$. hirsutum also increased during chilling, suggesting these plants are not totally insensitive to the stress, the values are generally lower than those measured for $\mathrm{H} 722$ plants and there was evidence that chilling-induced damage was repaired during the dark periods. In terms of a screening procedure, the maximum difference between chilling-susceptible and -tolerant material was seen at the end of the dark period of the 2 nd or 3 rd day. However, these differences are reduced once the plants are exposed to $>1 \mathrm{hr}$ of light under chilling conditions.

The diurnal pattern of change in the H722 Fo : Fp ratio corresponds to the diurnal change in chilling sensitivity that has previously been measured for tomato seedlings $(12,17)$. The Fo : Fp ratios measured for $\mathrm{H} 722$ indicate that the plants are most sensitive to chilling near the end of the dark period. It appears that H722 sustains increasing amounts of damage in each successive day due to its inability to repair damage during the dark 

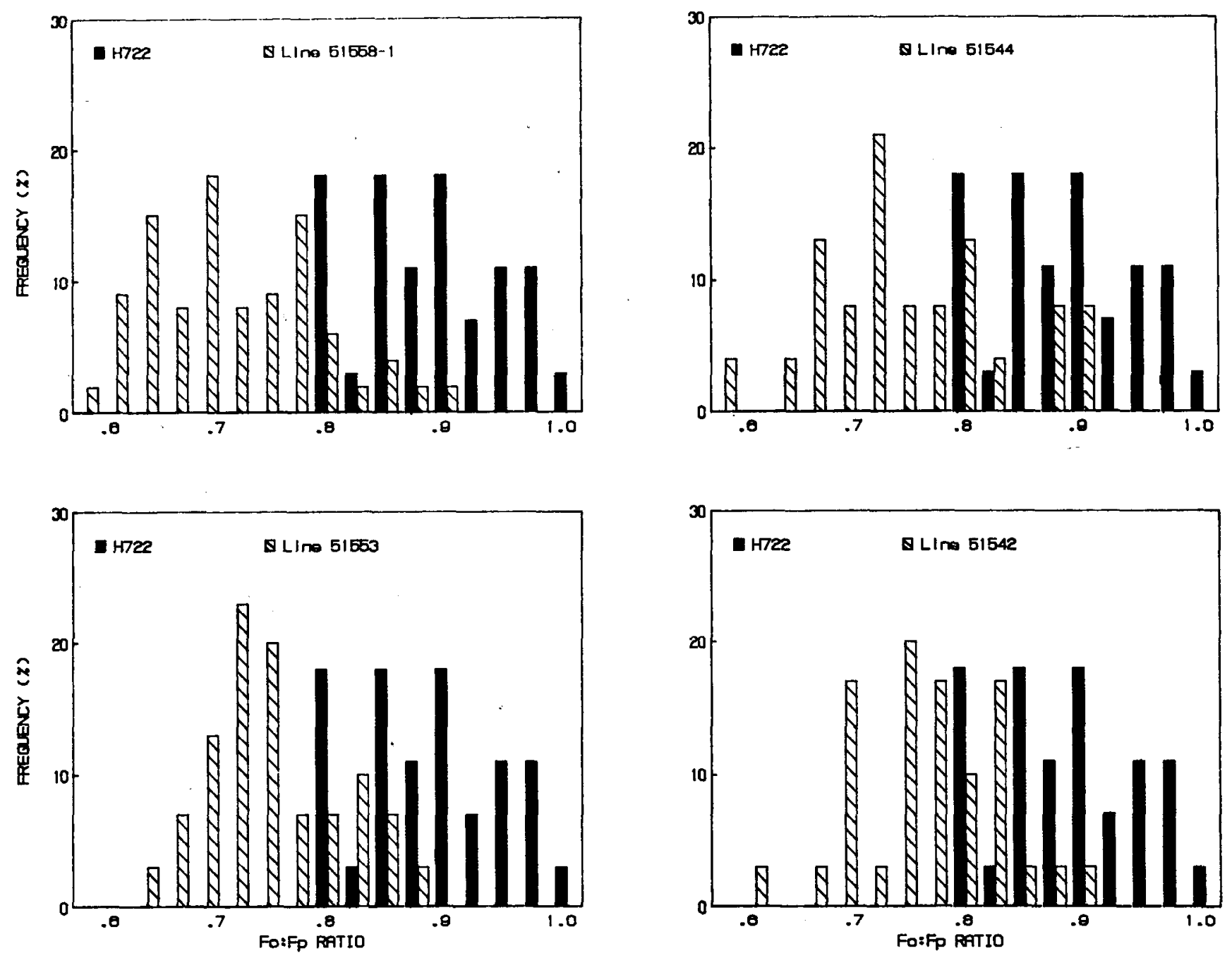

Fig. 4. The distribution of Fo : Fp ratios for at least 24 plants of four representative lines derived from a $L$. hirsutum $\times L$. esculentum cv. H722 cross (backcrossed twice to H722) compared to H722. The overall ranking of the four lines is depicted in Fig. 3.

period. The tolerance level of $L$. hirsutum may therefore be related to its ability to repair chilling-induced damage under dark, lowtemperature conditions. The repair mechanism(s) are not well-understood, but may involve the carbohydrate status of the plant. King et al. (11) have suggested that the increased sensitivity at the end of the dark period could be due to carbohydrate depletion, and that chilling tolerance following light exposure is likely due to carbohydrate accumulation or closely related events.

Figure 3 depicts the overall ranking of the plant material tested based on fluorescence measurements made on plants given a 3-day cold treatment at 2C. S. lycopersicoides (A) and the $F_{1}$ cross (B) had Fo : Fp values of 0.76 and 0.78 , respectively, which are substantially lower than the 0.88 and 0.90 recorded, respectively, for cultivars $\mathrm{H} 722(\mathrm{G})$ and $\mathrm{H} 2653(\mathrm{H})$. The Fo : Fp values for the $25 \mathrm{BC}_{2} \mathrm{~F}_{2}$ lines obtained from a $L$. hirsutum $\times \mathrm{H} 722$ cross (backcrossed twice to $\mathrm{H} 722$ ) range from 0.77 to 0.98 , suggesting that this population includes some tolerant and some extremely sensitive lines. The large standard errors associated with the Fo : Fp ratios may be a reflection of the heterogeneity that exists within the lines, and/or variation due to diurnal changes, since several hours are needed to complete the collection of data from whole plants.

The histograms in Fig. 4 show the intraline variability in the $\mathrm{Fo}_{\mathrm{O}} \mathrm{Fp}$ ratio for a few of the $\mathrm{BC}_{2} \mathrm{~F}_{2}$ lines (labeled C, D, E, and F in Fig. 3). Fo : Fp ratios were measured for at least 24 plants of these lines. For all four lines, the populations of plants tested are distributed over a wider range of Fo : Fp values than is seen for the H722 parental material. The greatest degree of overlap is seen in line 51542 , which is essentially equivalent to $\mathrm{H} 722$ in terms of low-temperature sensitivity. However, each of the four lines has members of its respective population that show tolerance levels close to that of $S$. lycopersicoides (Fig. 3). This observation suggests that recurrent selection from those members of the population that have the majority of Fo : Fp values $<0.80$ would result in a distinct chilling-tolerant population.

Some of the limitations of the current procedure are that the total number of plants that can be chilled at one time in a controlled environment is small, and that the whole plant is exposed to the low-temperature stress. For plant breeding, it would be desirable to have a screening procedure that does not damage the whole plant and can be applied to large populations of plants. These problems 'may be overcome by monitoring the effects of cold temperatures on the chlorophyll fluorescence profiles of detached leaves. The use of detached leaves would also reduce the total amount of time required to complete data collection, thereby minimizing the effects of diurnal changes in chlorophyll fluorescence.

Figure 5 demonstrates the similarity of the changes in Fo : Fp values measured for detached and attached leaves of two cultivated lines of tomato. Smillie et al. (22) have recently compared chilling injury and recovery in detached and attached leaves of beans and corn using the Fr parameter. They reported that the greatest chilling sensitivity occurred in fully turgid leaves, and for valid comparisons between detached and attached leaves it was necessary to ensure that the water status of all leaves was the same.

The present study indicates that chilling tolerance can be transferred by intergeneric 

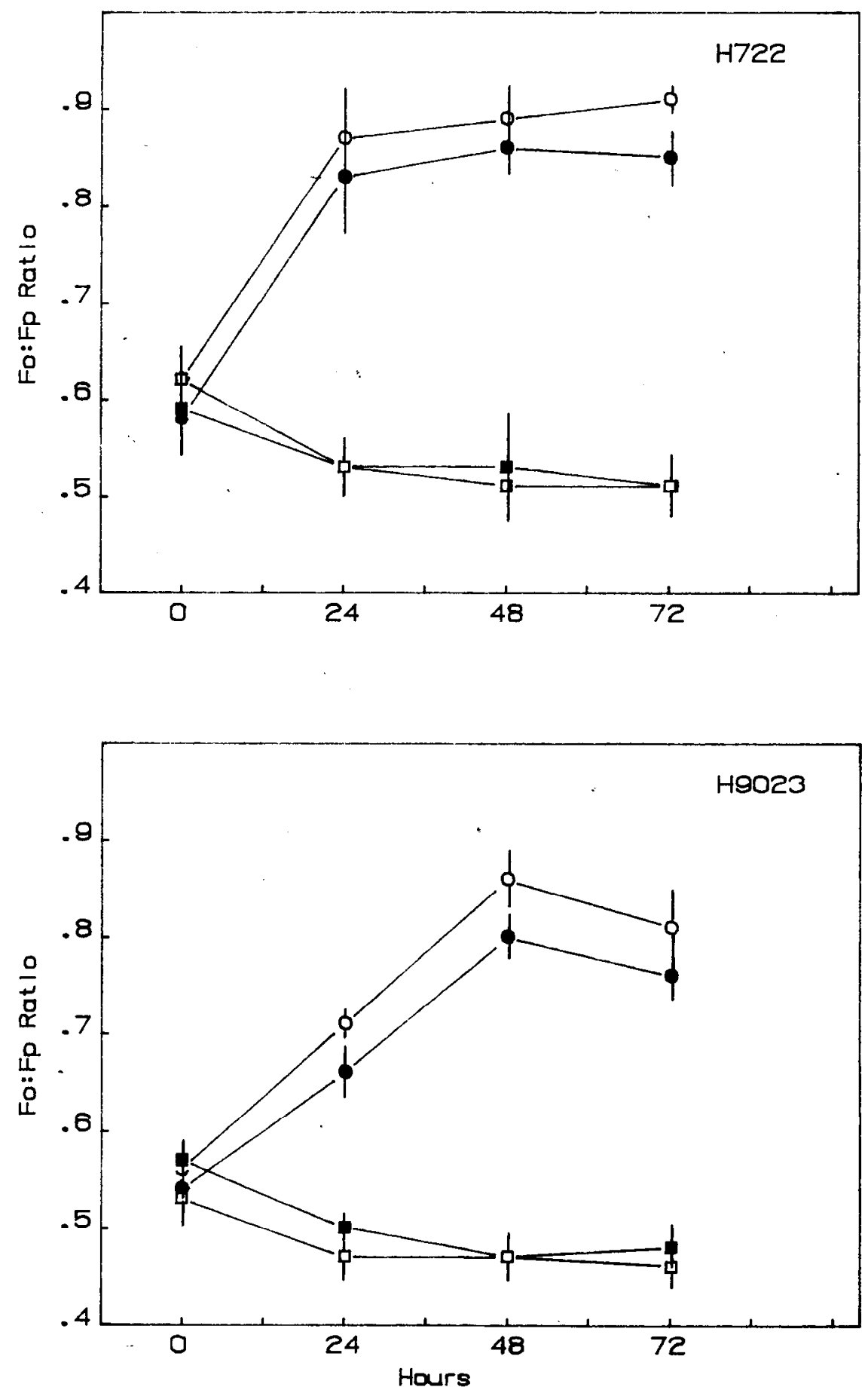

Fig. 5. Comparison of detached leaves and seedlings of H722 and H9023 to a low temperature stress of $2 \mathrm{C}$ over $72 \mathrm{hr}$. Values represent the mean of three replications \pm SE. Open symbols represent detached leaves. Solid symbols represent attached leaves; $\square, \boldsymbol{\square}=$ control at $25 \mathrm{C} ; \bigcirc, \boldsymbol{\bigcirc}=$ chilled at $2 \mathrm{C}$.

crosses in tomato and that a screening procedure based on the Fo : Fp ratio can identify tomato plants from the resulting segregating populations that possess chlorophyll fluorescence characteristics that are very similar to those of the chilling-tolerant $S$. lycopersicoides $(8,20,23)$. The results provide additional evidence $(21,22)$ that this experimental approach may be extended toward the use of detached leaves for the selection of chilling-tolerant material, and therefore enhance the usefulness of the assay for plant breeding.

\section{Literature Cited}

1. Bradbury, M. and N.R. Baker. 1981. Analysis of the slow phases of the in vivo chlorophyll fluorescence induction curve. Changes in the redox state of photosystem II electron acceptor and fluorescence emission from photosystems I and II. Biochim. Biophys. Acta 635:542-551.

2. Barber, J., D.N.H. Horler, and D.J. Chapman. 1981. Photosynthetic pigments and efficiency in relation to the spectral quality of absorbed light, p. 341-354. In: H. Smith (ed.). Plants and Daylight Spectrum. Academic, New York.
3. Duysens, L.N.M. and H.E. Sweers. 1963. The mechanism of two photochemical reactions in algae as studied by means of fluorescence. Studies on microalgae and photosynthetic bacteria. Jpn. Soc. Plant Physiol. Univ. of Tokyo Press, Tokyo. p. 353-372.

4. Geacintov, N.E. and J. Breton. 1987. Energy transfer and fluorescence mechanisms in photosynthetic membranes. CRC Crit. Rev. Plant Sci. 5:1-44.

5. Havaux, M. and R. Lannoye. 1984. Effects of chilling temperatures on prompt and delayed chlorophyll fluorescence in maize and barley leaves. Photosynthetica 18:117-127.

6. Havaux, M. and R. Lannoye. 1985. In vivo chlorophyll fluorescence and delayed light emission as rapid screening techniques for stress tolerance in crop plants. Z. Pflanzenzüchtg. 95:1-13.

7. Hetherington, S.E., R.M. Smillie, A.K. Hardacre, and H.A. Eagles. 1983. Using chlorophyll fluorescence in vivo to measure the chilling tolerance of different populations of maize. Austral. J. Plant Physiol. 10:247-256.

8. Kamps, T.L., T.G. Isleib, R.C. Herner, and K.C. Sink. 1987. Evaluation of techniques to measure chilling injury in tomato. HortScience 22:1309-1312.

9. Krause, G.H., C. Vernotte, and J.M. Briantais. 1982. Photoinduced quenching of chlorophyll fluorescence in intact chloroplasts and algae. Resolution into two components. Biochim. Biophys. Acta 679:116-124.

10. Krause, G.H. and E. Weis. 1984. Chlorophyll fluorescence as a tool in plant physiology: II. Interpretation of fluorescence signals. Photosyn. Res. 5:139-157.

11. King, A.I., D.C. Joyce, and M.S. Reid. 1988. Role of carbohydrates in diurnal chilling sensitivity of tomato seedlings. Plant Physiol. 86:764-768.

12. King, A.I., M.S. Reid, and B.D. Patterson 1982. Diurnal changes in the chilling sensitivity of seedlings. Plant Physiol. 70:211214

13. Lyons, J.M. 1973. Chilling injury in plants. Annu. Rev. Plant Physiol. 24:445-466.

14. Malkin, S., A. Telfer, and J. Barber. 1986 Quantitative analysis of state 1-state 2 transitions in intact leaves using modulated fluorimetry-evidence for changes in the absorption cross-section of the two photosysterns during state transitions. Biochim. Biophys. Acta 848:48-57.

15. Melis, A., A. Manodori, R.E. Glick, M.L Ghirardi, S.W. McCauley, and P.J. Neale. 1985. The mechanism of photosynthetic membrane adaption to environmental stress conditions: a hypothesis on the role of electron-transport capacity and of ATP/NADPH pool in the regulation of thylakoid membrane organization and function. Physiol. Veg. 23:757-765.

16. Papageorgiou, G. 1975. Chlorophyll fluorescence: an intrinsic probe of photosynthesis, p. 319-371. In: Govindjee (ed.). Bioenergetics of photosynthesis. Academic, New York.

17. Patterson, B.D., D. Graham, and R. Paull. 1979. Adaptation to chilling: survival, germination, respiration and protoplasmic dynamics, p. 25-35. In: J.M. Lyons, D. Graham, and J.K. Raison (eds.). Low temperature stress in crop plants-the role of the membrane. Academic, New York

18. Patterson, B.D., R. Paull, and R.M. Smillie. 1978. Chilling resistance in Lycopersicon hirsutum Humb. \& Bonpl., a wild tomato 
with a wide altitudinal distribution. Austral. J. Plant Physiol. 5:609-617.

19. Raison, J.K. and J.M. Lyons. 1986. Chilling injury: a plea for uniform terminology. Plant Cell \& Environ. 9:685-686.

20. Smillie, R.M. 1979. The useful chloroplast: a new approach for investigating chilling stress in plants, p. 187-202. In: J.M. Lyons,
D. Graham, and J.K. Raison (eds.). Low temperature stress in crop plants-The role of the membrane. Academic, New York.

21. Smillie, R.M. and S.E. Hetherington. 1983. Stress tolerance and stress-induced injury in crop plants measured by chlorophyll fluorescence in vivo; chilling, freezing, ice cover, heat and high light. Plant Physiol. 72:10431050 .
22. Smillie, R.M., R. Nott, S.E. Hetherington, and G. Oquist. 1987. Chilling injury and recovery in detached and attached leaves measured by chlorophyll fluorescence. Physiol. Plant. 69:419-428.

23. Wolf, S., D. Yakir, M.A. Stevens, and J. Rudlich. 1986. Cold temperature tolerance of wild tomato species. J. Amer. Soc. Hort. Sci. 111:960-964. 